\title{
Evaluation of expression changes, proteins interaction network, and microRNAs targeting catalase and superoxide dismutase genes under cold stress in rapeseed (Brassica napus L.)
}

\author{
Mohammad Mahdi Taghvaei* (1), Habibollah Samizadeh Lahiji(i) \\ and Mohammad Mohsenzadeh Golfazani(D) \\ Department of Plant Biotechnology, Faculty of Agriculture, University of Guilan, Rasht, Iran
}

Received 30 October 2020 - Accepted 29 November 2021

\begin{abstract}
Rapeseed is the third-largest source of plant oil and one of the essential oil plants worldwide. Cold stress is one of the critical factors that affect plant yield. Therefore, improving cold stress tolerance is necessary for yield increase. The present study investigated BnCAT1 and BnCSD1 genes' expression behavior in a tolerant and sensitive cultivar under cold stress $\left(4^{\circ} \mathrm{C}\right)$. Besides, protein-protein interaction networks of CATs and CSDs enzymes, and their association with other antioxidant enzymes were analyzed. Moreover, the microRNAs targeting $B n C A T 1$ and $B n C S D 1$ genes were predicted. This study indicated many direct and indirect interactions and the association between the components of the plant antioxidant system. However, not only did the CATs and CSDs enzymes have a relationship with each other, but they also interacted directly with ascorbate peroxidase and glutathione reductase enzymes. Also, 23 and 35 effective microRNAs were predicted for $B n C A T 1$ and $B n C S D 1$ genes, respectively. The gene expression results indicated an elevated expression of $B n C A T 1$ and $B n C S D 1$ in both tolerant and sensitive cultivars. However, this increase was more noticeable in the tolerant cultivar. Thus, the BnCSD1 gene had the highest expression in the early hour of cold stress, especially in the 12th h, and the BnCATl gene showed the highest expression in the 48th $\mathrm{h}$. This result may indicate a functional relationship between these enzymes.
\end{abstract}

Keywords: free radicals / gene expression / microRNA / protein interactions / string

\begin{abstract}
Résumé - Évaluation des changements d'expression, du réseau d'interaction des protéines et des microARN ciblant les gènes de la catalase et de la superoxyde dismutase en cas de stress lié au froid chez le colza (Brassica napus L.). Le colza représente la troisième source d'huile végétale et un oléoprotagineux essentiel dans le monde. Le stress lié au froid est l'un des facteurs critiques qui affectent le rendement des plantes. Par conséquent, l'amélioration de la tolérance au stress froid s'avère nécessaire pour augmenter le rendement. La présente étude a examiné la variation de l'expression des gènes BnCAT1 et BnCSD1 chez un cultivar tolérant et un autre sensible au stress lié au froid $\left(4{ }^{\circ} \mathrm{C}\right)$. En outre, les réseaux d'interaction protéine-protéine d'enzymes (catalase CAT et superoxide dismutase CSD), et leur association avec d'autres enzymes antioxydantes ont été analysés. De plus, les microARNs ciblant les gènes BnCAT1 et BnCSD1 ont été identifiés. Cette étude a souligné de nombreuses interactions directes et indirectes et l'association entre les composants du système antioxydant des plantes. Non seulement les enzymes CATs et CDSs étaient liées entre elles, mais elles interagissaient également directement avec l'ascorbate peroxydase et la glutathion réductase. De plus, respectivement 23 et 35 microARN étaient associés à une modification de l'expression des gènes BnCAT1 et BnCSD1. Les résultats de l'expression génétique ont indiqué une expression élevée de BnCAT1 et BnCSD1 chez les cultivars tolérants et sensibles. Cependant, cette augmentation était plus marquée chez le cultivar tolérant. Ainsi, le gène BnCSD1 avait l'expression la plus élevée dans les premières heures d'exposition au froid, en particulier à la $12^{\mathrm{e}} \mathrm{h}$, tandis que le gène BnCAT1 a montré l'expression la plus élevée à la $48^{\mathrm{e}} \mathrm{h}$. Ce résultat peut indiquer une relation fonctionnelle entre ces enzymes.
\end{abstract}

Mots clés : radicaux libres / expression génétique / microARN / interactions protéiques / colza

\footnotetext{
*Correspondence: mahdi.taghvaei@gmail.com
} 


\section{Highlight}

- BnCAT1 and BnCSD1 genes' expression pattern in two rapeseed cultivars under cold stress $\left(4^{\circ} \mathrm{C}\right)$ was investigated.

- Protein-protein interaction networks of CATs and CSDs enzymes, and their association with other antioxidant enzymes were analyzed.

- The microRNAs targeting BnCAT1 and BnCSD1 genes were predicted.

\section{Introduction}

Rapeseed has a significant place among annual oilseeds and is considered the most important annual oil plant in temperate, cold, and humid regions. Rapeseed is the thirdlargest source of plant oil in the world after soybeans and palm oil (Wanasundara et al., 2017). Plant growth and development are adversely altered by environmental stresses, including abiotic stresses (Raza, 2020). Abiotic stresses (drought, flood, salinity, oxidative, cold, heat, heavy metals) are the leading cause of global crop decline. They are responsible for the reduced yields of more than $50 \%$ of primary agricultural products (Raza et al., 2019, 2020a).

Cold stress is one of the main factors limiting the growth and production of crops; therefore, increasing crop cold tolerance is crucial to increase crop yield. Also, cold causes oxidative stress and leads to lipid peroxidation and chlorophyll degradation. Cold stress tolerance is associated with increased antioxidant activity and decreased hydrogen peroxide accumulation (Xie et al., 2019). Cold stress in plants is typically classified as chilling (above $0-15^{\circ} \mathrm{C}$ ) and freezing (below $0{ }^{\circ} \mathrm{C}$ ) (Thomashow, 1999).

Many cellular activities will be sufficiently damaged when a plant is exposed to unusually low temperatures. The first target of low-temperature damage is in the cell membrane of plants, transforming the membrane's physical state from the liquid crystalline phase to the gel-like solid phase. These changes occur in the cell membrane causing other changes in the cell or plant. The cold temperature causes intracellular ice crystals to form, disrupting the sensitive plant organs (Raza, 2020). Moreover, the cold affects the accumulation of reactive oxygen species (ROS). As the temperature decreases, enzymes and ROS inhibitory systems' activities will typically decrease. Therefore, the plant can't cope adequately with ROS production. Investigating influential factors in cell damage has shown that ROS are the principal causes of damage during abiotic stresses, leading to changes in the factors involved in preserving membrane compounds, antifreeze compounds, antioxidants, and many other processes (Hasanuzzaman et al., 2020; He et al., 2021). Excessive production of reactive oxygen species under cold stress can cause severe oxidative damage to plants. Antioxidant defense mechanisms have been developed in plants to reduce ROS's adverse effects on plant cells (Kalisz et al., 2016; Rezaie et al., 2020). Accumulation of ROS will have detrimental impacts, primarily on membranes, and can lead to ion leakage. Besides, low temperatures cause the formation of secondary structures in RNA, therefore affecting gene expression. Moreover, the freezing temperature will have far more destructive effects (Gusta et al., 2004). Plants have developed their antioxidant defense mechanism to maintain ROS's balance because an excessive increase in ROS leads to the loss of key intracellular signaling molecules (Xie et al., 2019).

ROS, such as hydrogen peroxide $\left(\mathrm{H}_{2} \mathrm{O}_{2}\right)$, superoxide $\left(\mathrm{O}_{2}{ }^{-}\right)$, and hydroxyl radicals $\left(\mathrm{HO}_{2}\right)$, are oxygen $\left(\mathrm{O}_{2}\right)$ derivatives that are more reactive and are considered general responses to biotic and abiotic stresses. ROS are naturally produced in chloroplasts, mitochondria, plasma membranes, apoplasts, endoplasmic reticulum, peroxisome, and cell wall. Therefore, the plant should maintain its scavenging systems to deal with these destructive factors. Several studies have confirmed the critical importance of the intracellular antioxidant defense system against various stresses (Cavallini et al., 2016; Hasanuzzaman et al., 2020). The antioxidant defense system includes enzymatic and non-enzymatic components for ROS inhibition in various intracellular organs like chloroplasts, peroxisomes, plasma membranes, and endoplasmic reticulum (Sharma et al., 2012). Enzymatic antioxidants contain enzymes like superoxide dismutase (SOD), catalase (CAT), glutathione peroxidase (GPX), ascorbate peroxidase (APX), guaiacol peroxidase (GPOX), Monohydro ascorbate reductase (MDHAR), dehydroascorbate reductase (DHAR), and glutathione S-transferases (GST). Non-enzymatic antioxidants include ascorbic acid, glutathione, carotenoids, tocopherols, proline, glycine, and glutathione (Pandey et al., 2017).

Superoxide dismutase enzymes act as antioxidants and preserve cellular components against ROS (Alscher et al., 2002). When an $\mathrm{O}_{2}$ molecule absorbs an electron from the transfer chain, it is reduced to $\mathrm{O}_{2}{ }^{-}$. Superoxide is a disruptive factor for enzymes, DNA, and lipid oxidation (Smirnof, 1993). SOD catalyzes the production of $\mathrm{O}_{2}$ and $\mathrm{H}_{2} \mathrm{O}_{2}$ from superoxide and consequently reduces its adverse effects. SOD concentrations typically rise with increasing levels of oxidative stress. Dividing the various forms of SOD helps the plant to neutralize stress much more effectively. Catalase is an antioxidant enzyme found in all aerobic organisms that catalyze the efficient conversion of $\mathrm{H}_{2} \mathrm{O}_{2}$ to water and oxygen in organic cells exposed to environmental stress. Catalase exists in all major production sites of $\mathrm{H}_{2} \mathrm{O}_{2}$ in plant cells (such as peroxisomes, mitochondria, cytosols, and chloroplasts). Many molecular forms of catalase isoenzymes indicate their significant role in the plant system. The critical point about this enzyme is that it is mainly active at high concentrations of $\mathrm{H}_{2} \mathrm{O}_{2}$ (Sharma, 2014). It seems these two antioxidant enzymes (CAT and SOD) cooperate for the detoxification of ROS (Fig. 1) (Sewelam et al., 2016). These possible associations can be examined by analyzing protein interaction networks. Protein-protein interaction networks are examined as a valuable indicator for adequately understanding cellular processes. Fundamentally, proteins act as a network interacting with each other (Taghvaei et al., 2019). MicroRNAs are one of the most critical post-transcriptional regulatory elements. These 21 to 22 nucleotide sequences regulate the activity of the gene by complementing with their mRNA. In other words, the complete binding with the target region leads to cleavage, and in the case of incomplete binding, it prevents the translation of the target gene (Bartel, 2004). 


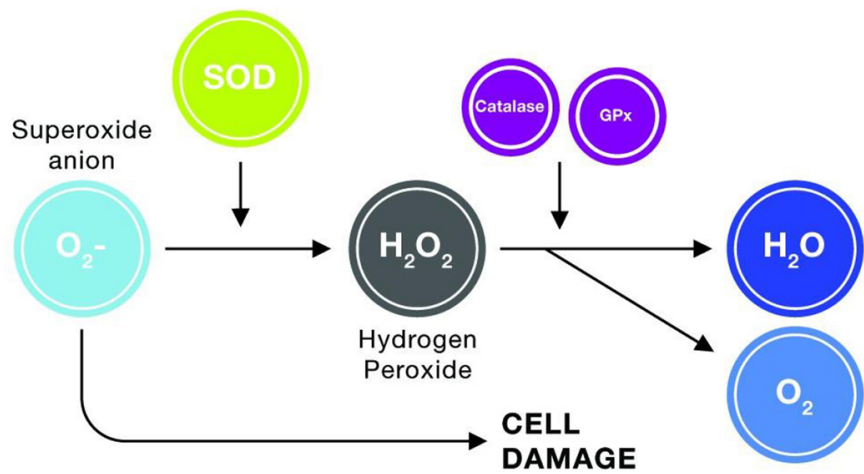

Fig. 1. The relationship between superoxide dismutase activity and catalase-SOD enzyme converts the superoxide radical to hydrogen peroxide, and catalase converts hydrogen peroxide to water (Sewelam et al., 2016).

It is required to examine protein interactions and genes and other factors involved in stress-responsive systems to produce stress-tolerant plants. Rapeseed has a complicated genome as a result of its evolutionary history, making it an attractive genome for plant breeding research (Raza et al., 2020b). Abiotic stresses are the most crucial factors affecting rapeseed's yield. So, it is essential to investigate cold tolerance mechanisms and the role of cold-tolerant genes in rapeseed. In the plant's response to cold stress, the antioxidant defense system is of great importance. Valuable and comprehensive studies can be done using bioinformatics studies, protein network analysis, and microRNAs investigation as the most important post-transcriptional gene regulators. Therefore, the present study was conducted to clarify the relationships and interactions in the antioxidant defense system and the altered gene expression behavior under cold stress in sensitive and tolerant cultivars.

\section{Materials and methods}

\subsection{Investigation of protein interactions}

In the present study, to investigate the interactions of proteins in the antioxidant defense system of rapeseed, their information and genetic identity were taken using the UniProt database. Afterward, it was used in the STRING database to identify protein-protein interactions (PPIs). This database contains information from various sources, including experimental data, computational forecasting methods, and it is updated continuously. In this database, each interaction is given a score of 0 to 1 , the minimum required interaction score was set to the highest (0.7) (Szklarczyk et al., 2019; Taghvaei et al., 2019).

\subsection{Phylogenetic tree construction}

To investigate and compare the evolutionary relationships of different types of catalase and superoxide dismutase enzymes between Brassica napus and Arabidopsis thaliana, the existing sequences of Catalase $1(C A T 1)$ and Superoxide dismutase $[\mathrm{Cu}-\mathrm{Zn}] 1$ (CSD1) were taken from the NCBI database. ClustalW was used for the alignment of the sequences (Thompson et al., 1994). The results of alignment were used to construct phylogenetic trees by MEGAX software (Kumar et al., 2018) using the Neighbor-joining (NJ) method and Bootstrap analysis with 1000 replications (Gupta et al., 2019).

\subsection{Prediction of microRNAs}

To identify microRNAs targeting BnCAT1 and BnCSD1 genes, psRNATarget online database 2017 was used (the expectation parameter was set to 4). Hence, all identified plant microRNA sequences (miRBase Release 22.1, October 2018) were used to search for $B n C A T 1$ and $B n C S D 1$ genes. In this study, microRNAs sequences were given to the software to find targeting the genes. This platform is specifically designed to predict microRNAs and target genes in plants (Dai et al., 2018). Besides, Cytoscape software version 3.8 was used to map the relationship between the predicted microRNAs and the studied genes (Shannon et al., 2003).

\subsection{Plant materials and treatment conditions}

Two cultivars of canola, Sarigol (sensitive) and Zarfam (tolerant) were selected (Safaei et al., 2018). The cultivars' seeds were obtained from the seed and plant improvement institute (Karaj, Iran). The seeds were sterilized by immersing them in $70 \%$ ethanol for 1 minute and in sodium hypochlorite solution (5\%) for 1 minute, then washing with deionized sterile water (Gao et al., 2016). The seeds were then placed in a growth chamber at $25^{\circ} \mathrm{C}$ (Biotechnology Laboratory of the Faculty of Agriculture, University of Guilan, Iran). Afterward, healthy germinated seeds were transferred to pots for hydroponic cultivation. A closed hydroponic system and Hoagland nutrient solution at half concentration were used for plant cultivation (Epstein and Bloom, 2004). Two rapeseed plant cultivars, "Zarfam" (a cold-tolerant cultivar) and "Sarigol" (a cold-sensitive cultivar), were culture-grown under a 16 -h light $\left(25^{\circ} \mathrm{C}\right) / 8$-h dark $\left(22^{\circ} \mathrm{C}\right)$ photoperiod (photo intensity $6000 \mathrm{Lx}$ ). Plants were exposed to $4^{\circ} \mathrm{C}$ for $0,4,8,12$, 24 , and $48 \mathrm{~h}$ to analyze the antioxidant genes of rapeseed under cold stress. In the case of controls, plants were exposed to $25^{\circ} \mathrm{C}$ for $0,4,8,12,24$, and $48 \mathrm{~h}$. The treated and untreated juvenile leaves were then harvested into liquid nitrogen and stored at $-80^{\circ} \mathrm{C}$ (Megha et al., 2018).

\subsection{Extraction of RNA and synthesize of cDNA}

RNA extraction was performed with TRIzol reagent (Invitrogen, USA) according to the manufacturer's instructions. The extracted RNA's quantity and quality were examined by Nanodrop ${ }^{\circledR}$ One (Thermo Fisher Scientific ${ }^{\circledR}$ ) and $1 \%$ agarose gel electrophoresis. DNase I.Rnase-free (Sinaclon, Iran) was used to remove genomic DNA contamination. Consequently, the First Strand cDNA Synthesis kit (Sinaclon, Iran) was used to make cDNA. After cDNA synthesis, the tube was transferred to $\mathrm{a}-80{ }^{\circ} \mathrm{C}$ freezer. 
Table 1. Specifications of primers used in real-time PCR reaction.

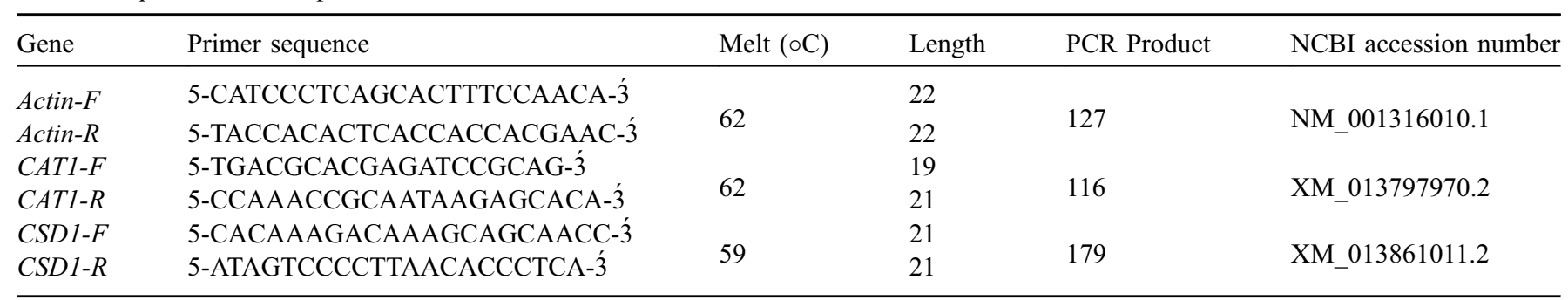

\subsection{Design of specific primers}

To design the primers, BnCAT1, BnCSD1, and BnActin (as a reference gene) sequences were obtained from the NCBI database. The primers were designed using Oligo 7 and Primer3 software. Furthermore, the sequence of the primers and their melting temperature were evaluated by Oligo analysis and finally checked for specificity in NCBI PrimerBLAST (Tab. 1).

\section{7 qRT-PCR analysis of gene expression}

The expression of candidate genes was examined by realtime PCR in Zarfam (tolerant) and Sarigol (sensitive) cultivars. The qRT-PCR was performed using an SYBR Green qPCR 2X (Sinaclon, Iran). The reactions were carried out in a LightCycler 96 real-time PCR machine (Roche, Basel, Switzerland) with the following amplification conditions: activation at $50^{\circ} \mathrm{C}$ for $2 \mathrm{~min} ; 95^{\circ} \mathrm{C}$ for $2 \mathrm{~min}$; followed by 40 cycles at $95^{\circ} \mathrm{C}$ for $15 \mathrm{~s}$ and $58^{\circ} \mathrm{C}$ for the $20 \mathrm{~s}$; and $72^{\circ} \mathrm{C}$ for $15 \mathrm{~s}$ and final holding at $4{ }^{\circ} \mathrm{C}$. All reactions were performed in three biological replicates, each with three technical replicates. The qRT-PCR results were normalized as follows: sample CT values were determined and standardized based on the actin gene control prime reaction, and the $2^{-\Delta \Delta \mathrm{CT}}$ method was applied to calculate the relative changes in gene expression from qRT-PCR experiments (Schmittgen and Livak, 2008). Statistical analysis was performed using a split-plot design in time by SAS software, Version $[9,4]$.

\section{Results and discussion}

\subsection{Protein-protein interactions}

This study investigates the protein interactions between enzymes involved in the rapeseed's antioxidant system (especially catalase and superoxide dismutase). Therefore, the STRING platform was used, in which nodes represent proteins and connections representing known or predicted and direct or indirect interactions. The relationship between the nodes was based precisely on the present information extracted from relevant databases and articles. By default, this network specifies all protein interactions with the minimum required interaction score of 0.4. However, a stricter coefficient $(0.7)$ was used in the present study to increase the interactions' accuracy. Subsequently, the interactions between three CAT and eight SOD enzymes showed 11 nodes and 45 edges (Fig. 2), all located in the network. Results indicated that these two groups of antioxidants were closely related to each other.

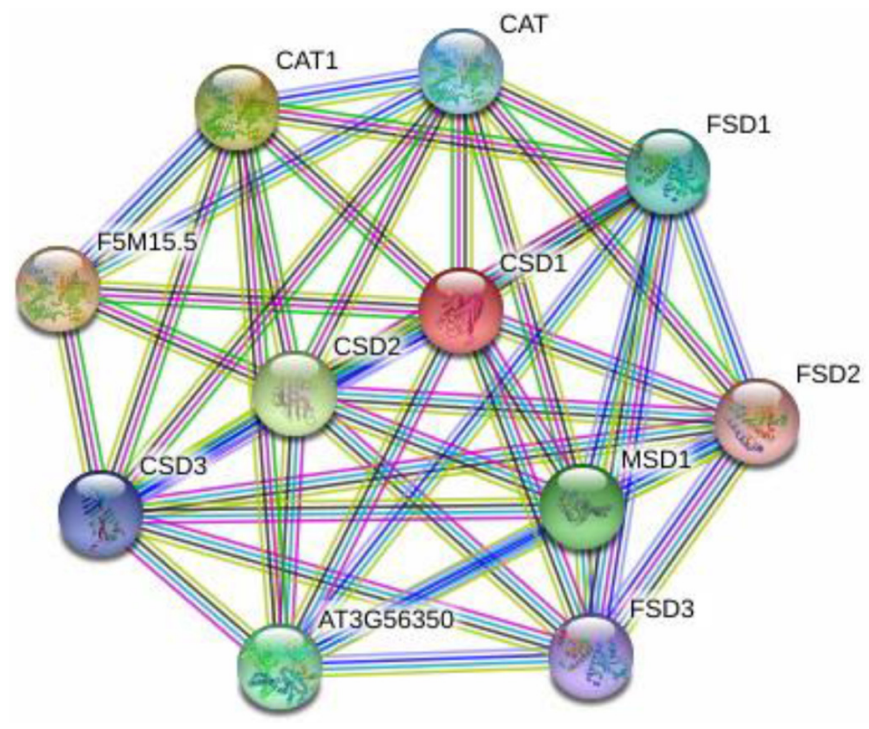

Fig. 2. Protein-protein interaction network of catalase and superoxide dismutase enzymes using the STRING database, colored nodes represent proteins, and colored lines represent their interactions based on the references the database.

As shown in Figure 2, there was a direct interaction between CAT and CSD enzymes. Besides, the relationship between CAT and CSD enzymes and known enzymes of the rapeseed's antioxidant system was examined, including catalase enzymes, superoxide dismutase enzymes, APX enzymes, MDHAR, DHAR, GST, and glutathione reductase (GR). As a result, 35 nodes and 192 edges were observed (Fig. 3), and all proteins were located in the network. As shown in Figure 3, the CAT1 enzyme interacted directly with the SOD, GR, and APX1 groups. The CSD1 enzyme interacted directly with both the catalase group and the GR and ascorbate peroxidase (APX6, APX2, APX1) enzyme groups. These results indicated the extensive and dependent relationship of enzymes involved in the plant's antioxidant defense system.

\subsection{Evolutionary analysis}

Arabidopsis shares a recent common ancestry with many species, including various oil-producing crops, most of which are Brassica species (Parkin et al., 2005). Rapeseed originated from interspecific hybridization between B.rapa and B. oleracea. After this genome collision, B. napus sustained 


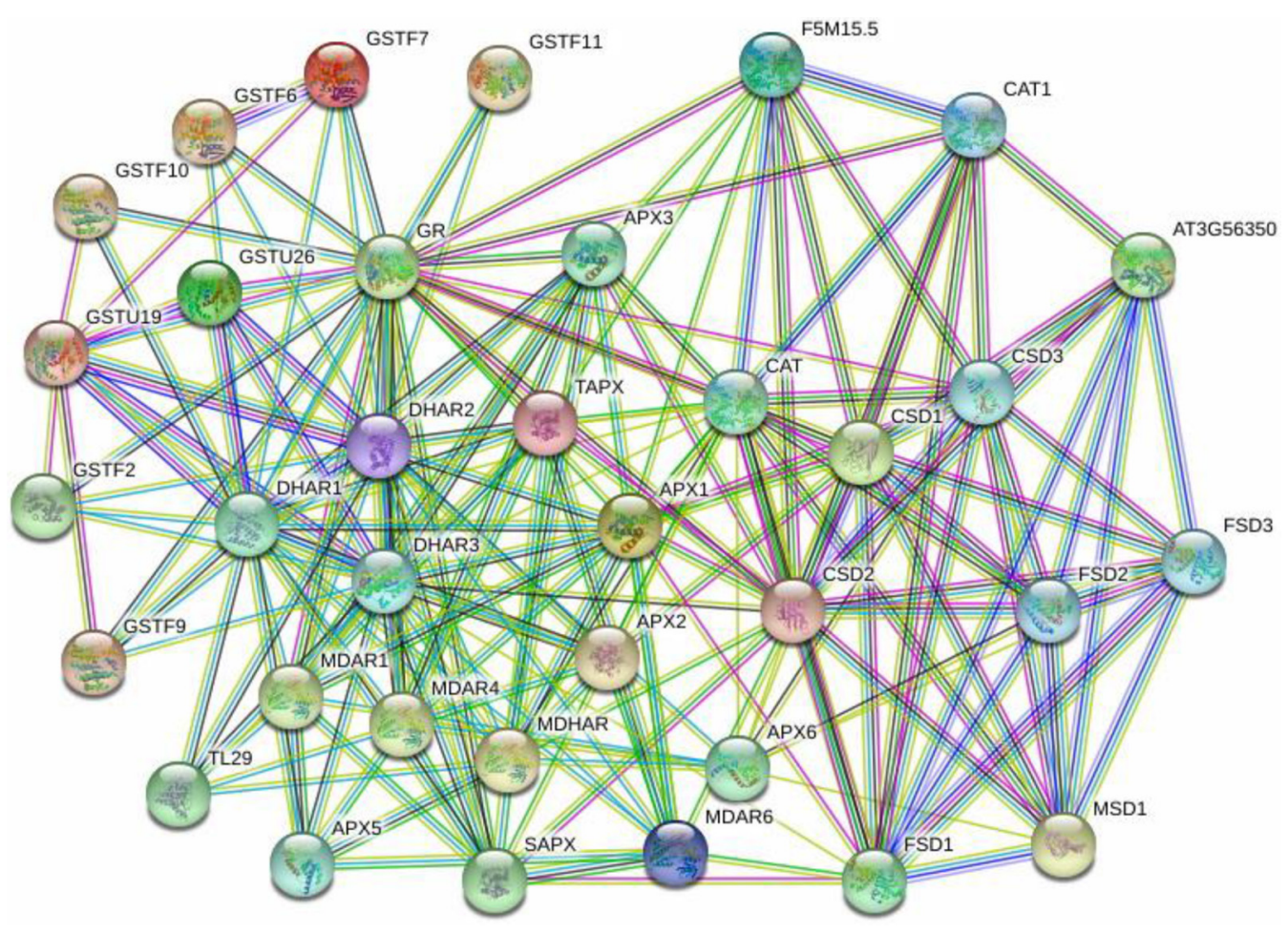

Fig. 3. Protein-protein interaction network using the STRING database to investigate the relationships between catalase and superoxide dismutase enzymes with other rapeseed's antioxidant groups. Colored nodes represent proteins, and colored lines represent their interactions with each other based on the references in the database.

a

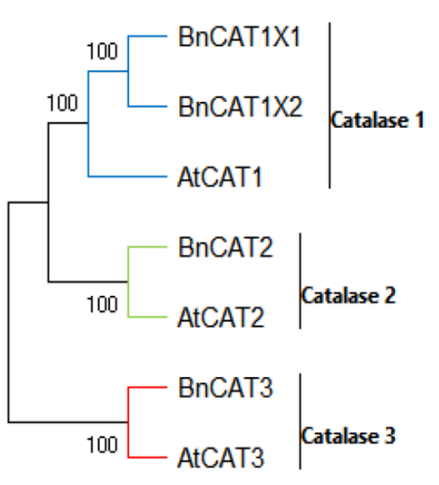

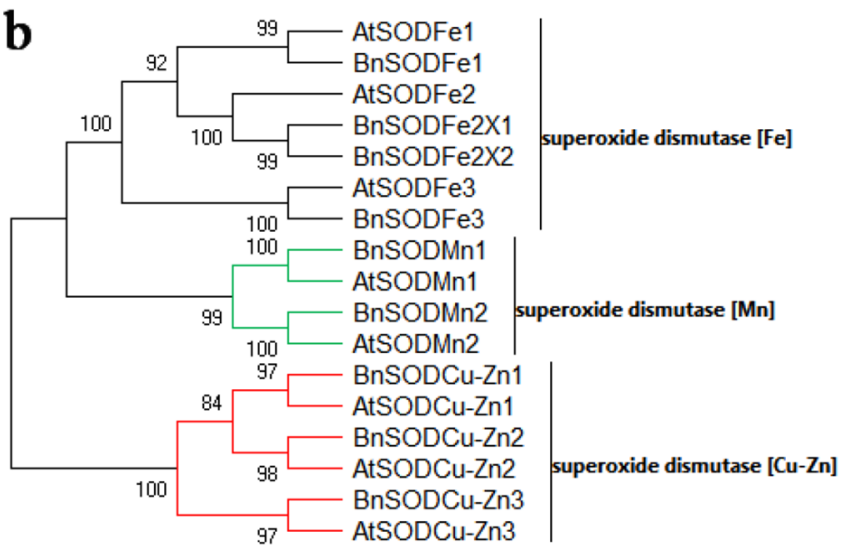

Fig. 4. Constructed phylogenetic trees for two groups of enzymes in Brassica napus (Bn) and Arabidopsis thaliana (At): (a) catalase and (b) superoxide dismutase. Multiple alignment was performed using ClustalW software, and tree construction was performed using MEGA X software with NJ method and Bootstrap test with 1000 replications.

vast genome restructuring via homoeologous chromosome exchanges, resulting in widespread segmental deletions and duplications (Lee et al., 2020). The evolutionary relationships were investigated using known sequences in the NCBI database (BnSODs, BnCATs, AtSODs, and AtCATs). It was observed that the BnSODs and BnCATs showed a phylogenetic relationship with AtSODs and AtCATs in each group (Fig. 4). However, in recent studies, genome-wide analysis of the Brassica napus genome was performed. As a result, they classified $B n C A T S$ into four groups, including
$14 B n C A T s$ and $B n S O D s$ into three groups, including 31 $B n S O D$ genes (14 BnCSDs, $11 B n F S D s$, and six BnMSDs). Besides, they found the BnSODs and BnCATs have a closer phylogenetic relationship with the Brassica oleracea (BolCATs and BolSODs) and Brassica rapa (BraCATs and BraSODs) in each group. Collinearity investigation exhibited strong orthologs of SOD genes and CAT genes among B.napus and three closely related species (B. rapa, B. oleracea, and A.thaliana) (Raza et al., 2021; Su et al., 2021). 


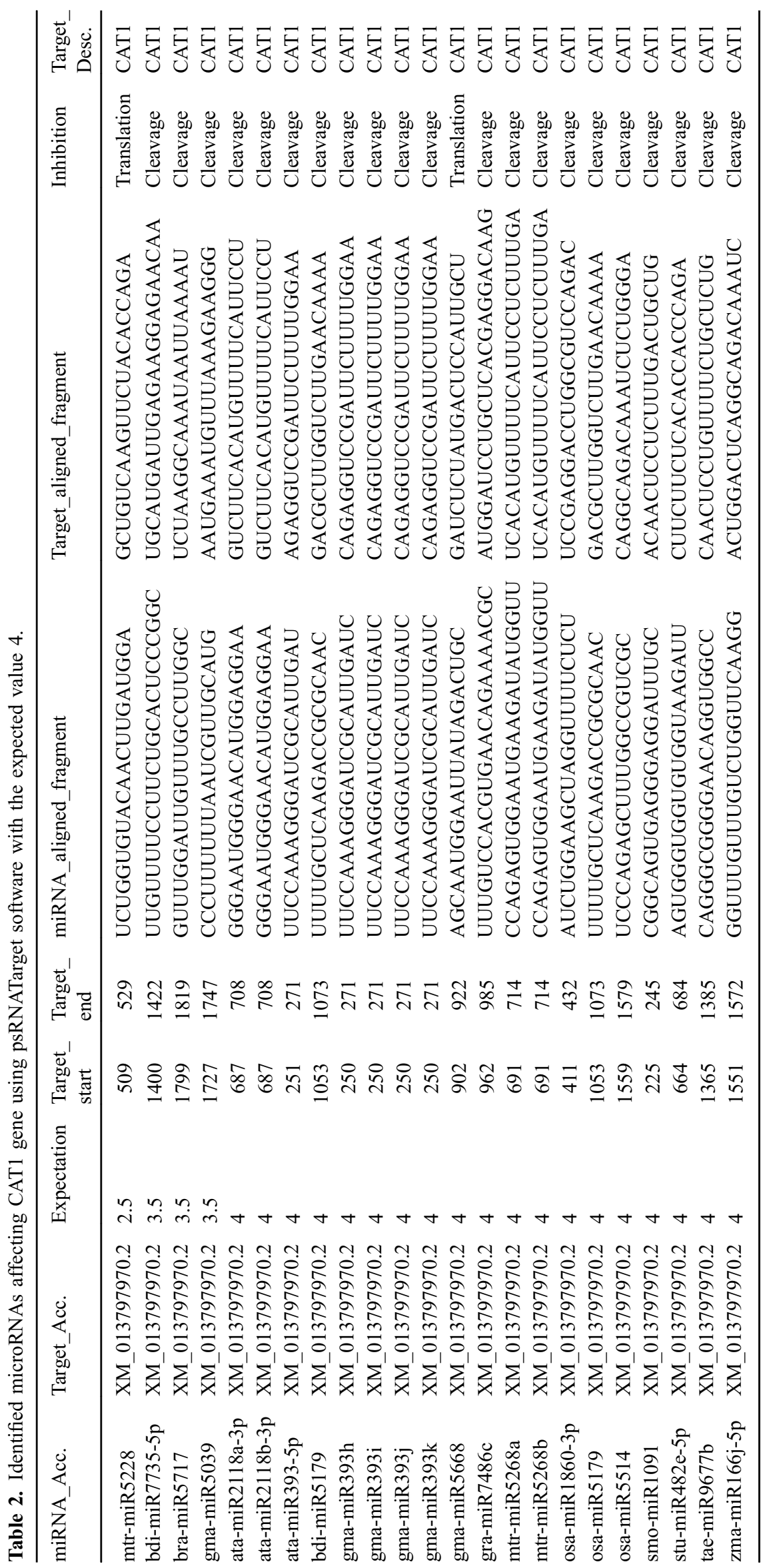




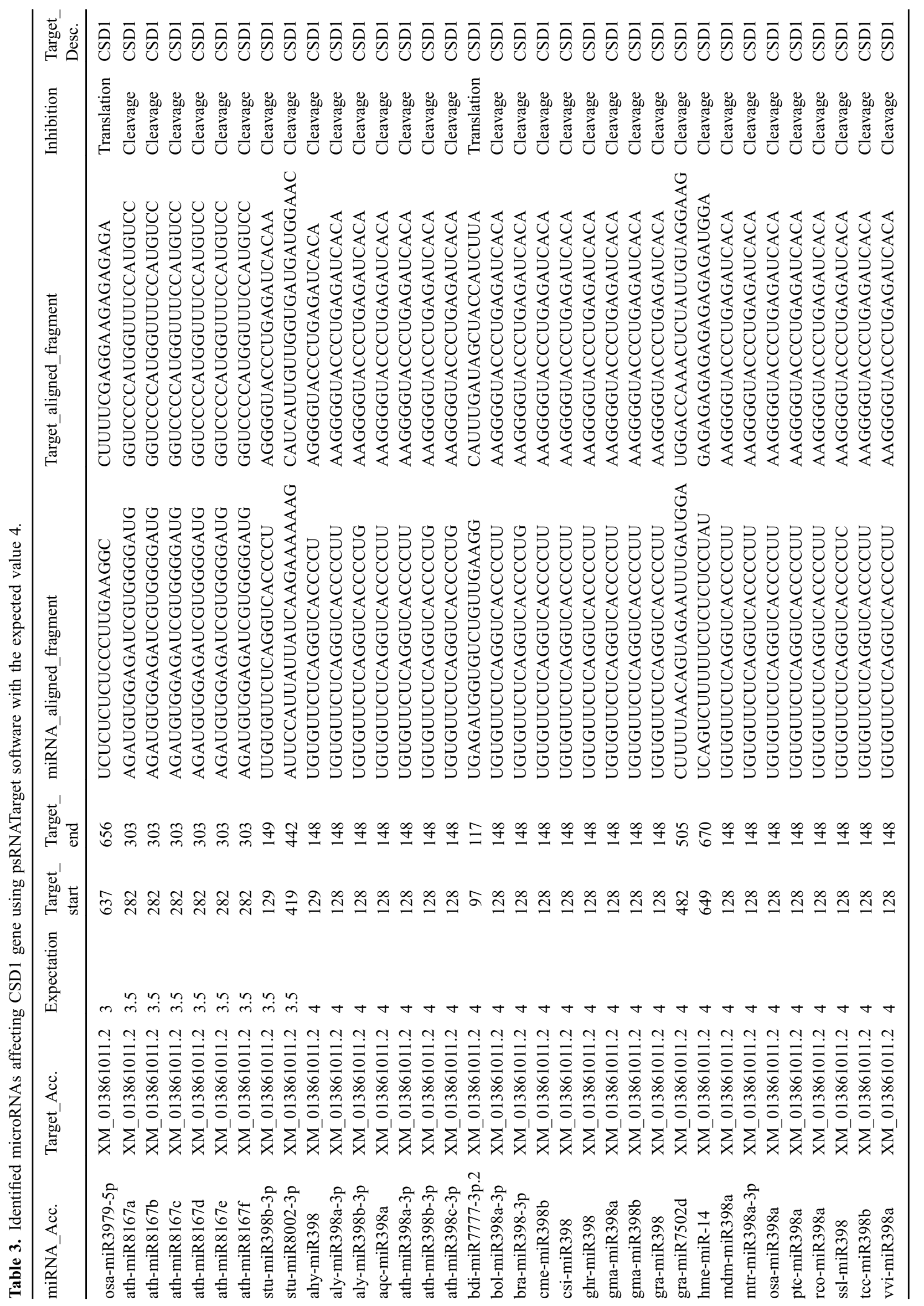



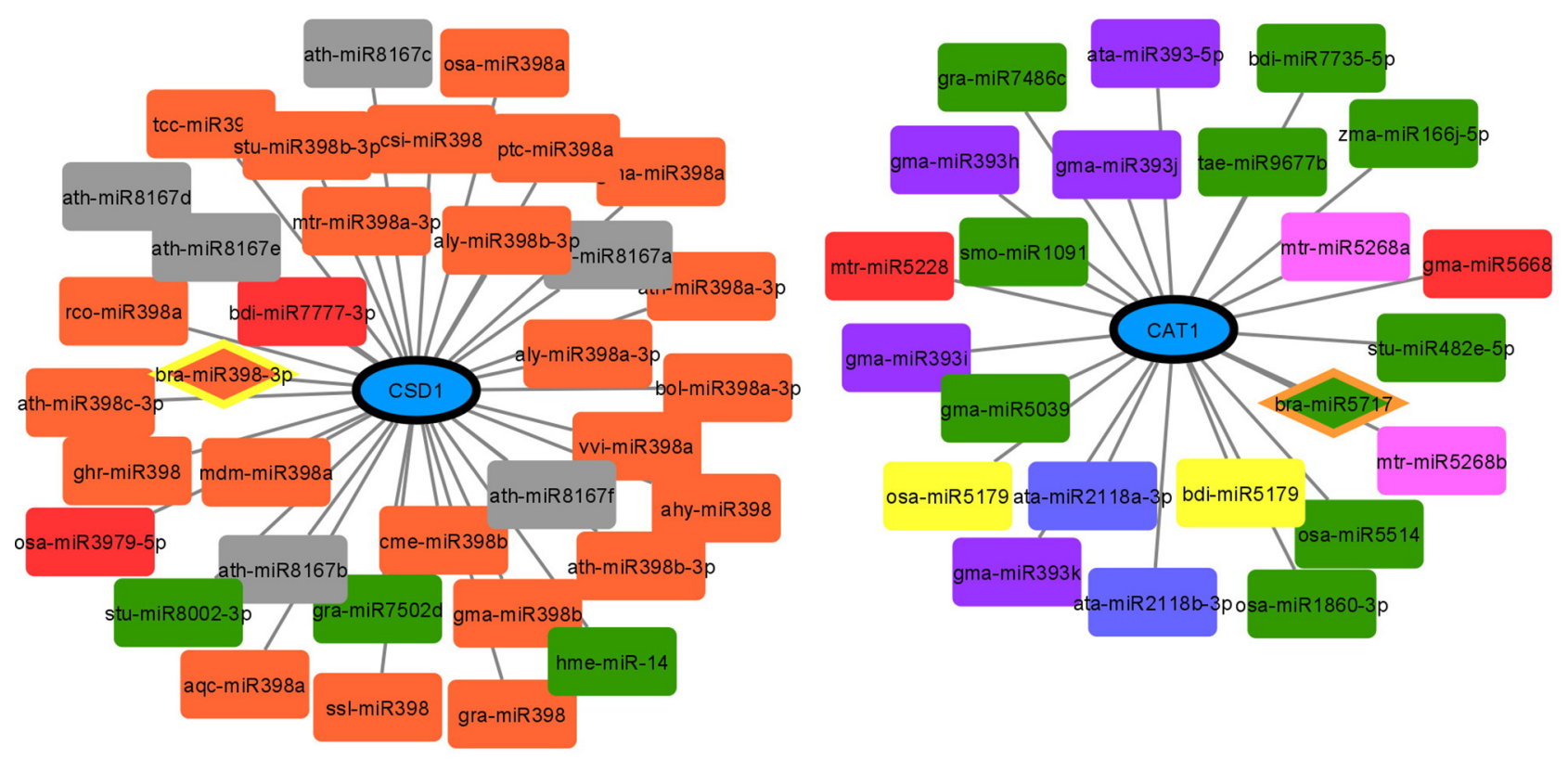

Fig. 5. Relationships between microRNAs affecting $B n C A T 1$ and $B n C S D 1$ genes were mapped using Cytoscape software. The figure on the right represents the $B n C A T 1$ gene, and the left figure represents the BnCSD1 gene. The red color indicates microRNAs that block gene translation, the rhombus shapes represent microRNAs observed in rapeseed under cold stress (Megha et al., 2018), and the green color indicates Individually located microRNAs, other groups with the same color represent the microRNA family.

\subsection{MicroRNAs targeting BnCAT1 and BnCSD1}

Regulation of gene expression at the post-transcriptional and post-translational levels carries a significant role in plant response to stress. MicroRNAs are one of the posttranscriptional regulators of gene expression, which perform an essential role in responding to abiotic stresses. MicroRNAs exert their regulatory activity by cleaving target mRNAs or inhibiting translation. In other words, the presence of complementary bases between the target gene and miRNA is a key factor in miRNA's functional mechanism. According to previous studies, complete complementarity of bases between target genes and miRNA leads to cleavage of the target gene. An incomplete pairing of bases prevents translation of the target gene transcript (Bartel, 2004). MicroRNAs are evolutionarily conserved in plant species and usually belong to conserved evolutionary families (Millar and Waterhouse, 2005; Moran et al., 2017). Therefore, microRNAs identified in other plant species can be used for preliminary and bioinformatics studies. psRNATarget was developed to identify plant sRNA targets by (1) analyzing complementary matching between the sRNA sequence and target mRNA sequence using a predefined scoring schema and (2) by evaluating target site accessibility (Dai et al., 2018). Therefore, microRNAs targeting BnCAT1 and BnCSDI genes were predicted (Tabs. 2 and 3). Also, the detailed information of the identified miRNAs is presented in Supplementary Material Table S1 and Table S2. The relationships between microRNAs and target genes have been shown in Figure 5. The results indicated that the $B n C S D 1$ gene was regulated by 35 types of microRNAs in plants. Most of them (24) belonged to the well-known and highly conserved family of miR398, followed by the miR8167 family. Nevertheless, miR398 was identified as a regulator for this gene in rapeseed. Among these microRNAs, only two of them regulated gene activity by inhibition of translation. In the recent study, 30 miRNAs from seven families targeting 13 BnSODs genes were bioinformatically identified in $B$. napus. Their results showed that the bnamiR159 family targeted $B n C S D 7, B n C S D 14$, and bna-miR166 family targeted $B n C S D 10$, and bna-miR172 family targeted $B n C S D 2$, and bna-miR397 family targeted BnCSD10 (Su et al., 2021). In previous studies, miR398 and miR8167 families have been mentioned as the $\mathrm{Cu} / \mathrm{Zn}$-SOD's primary regulators (Gupta et al., 2019). However, miR398 has been identified in several studies as one of the most effective microRNAs in the cold (Sunkar and Zhu, 2004; Liu et al., 2008; Cao et al., 2014; Wang et al., 2014; Sun et al., 2015; Megha et al., 2018). As well, the examination of the BnCATI gene revealed that this gene was targeted by 23 regulatory microRNAs. On the contrary, the diversity of microRNAs targeting this gene was more than the $B n C S D 1$ gene. However, the highest abundance of microRNAs targeting $B n C A T 1$ was related to the miR393 family. According to the previous research, this conserved microRNA family's role in responding to cold stress had been identified (Sunkar and Zhu, 2004; Zhang et al., 2014; Koc et al., 2015; Liu et al., 2017). Also, in the recent study, five members of the bna-miR166 family and one member of the bna-miR393 family targeting three $C A T$ genes (BnCAT4, BnCAT6, and BnCAT8) were bioinformatically identified in B. napus (Raza et al., 2021). Furthermore, in other research, expression change of miR166 in cassava under cold and drought stresses conditions and in Chinese cabbage under heat stress conditions was observed (Li et al., 2017). On the other hand, the role of miR398, miR5717, and miR393 in rapeseed, in response to cold stress, has been proven by miRNA sequencing (Megha et al., 2018). 

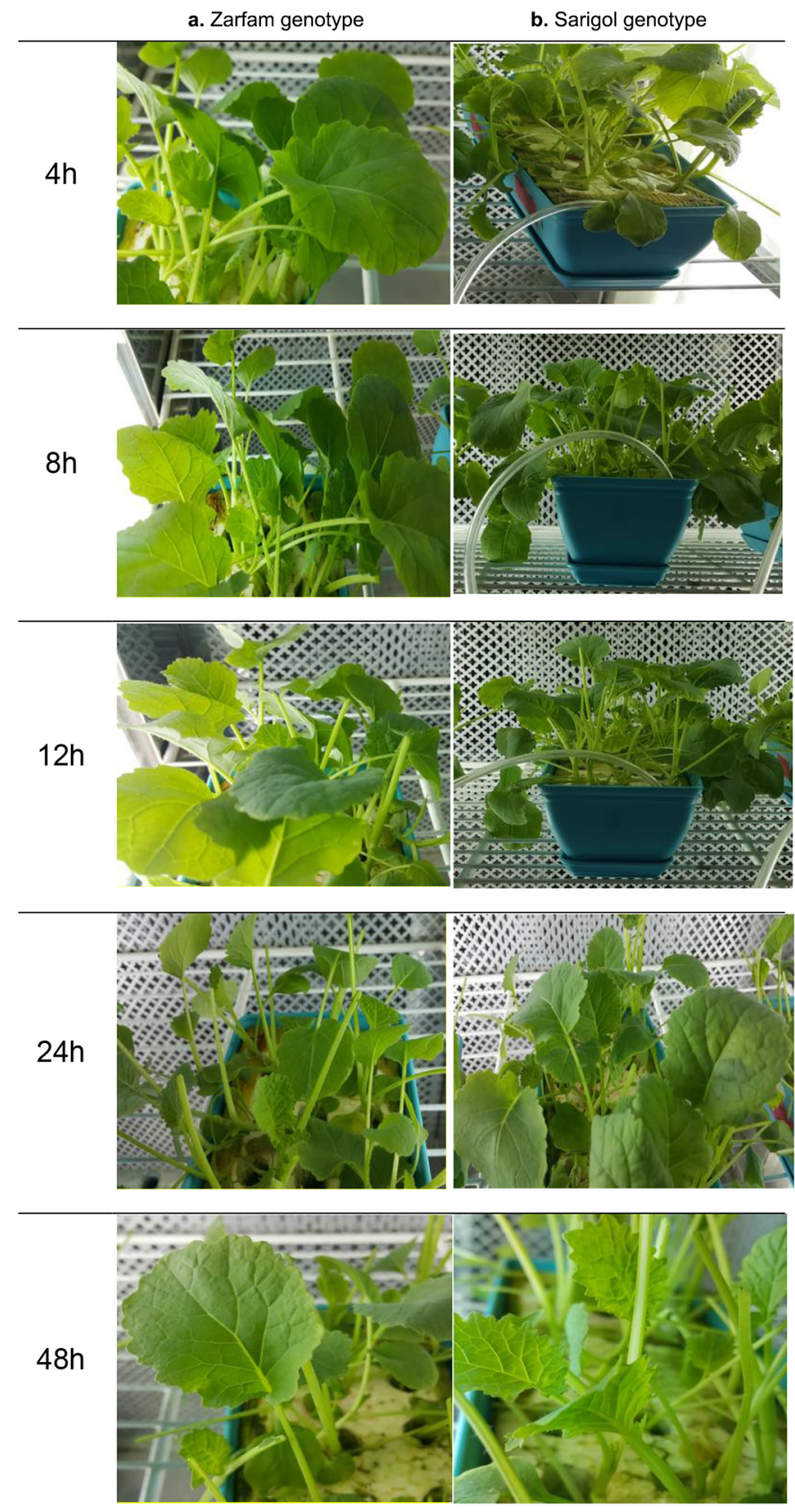

Fig. 6. Cold treatment $\left(4^{\circ} \mathrm{C}\right)$ on two Brassica napus cultivars in a period of $48 \mathrm{~h}$ ( $16 \mathrm{~h}$ of light and $8 \mathrm{~h}$ of darkness). (a) left side: Zarfam genotype and (b) right side: Sarigol genotype.

\subsection{Morphological changes in plants at $4{ }^{\circ} \mathrm{C}$}

The previous study on Zarfam and Sarigol cultivars at $-4^{\circ} \mathrm{C}$ found that freezing temperature stress has specific morphological effects on the Sarigol cultivar. In Sarigol seedlings, dehydration and wilting of plants were observed in the 4-6h after cold treatment $\left(-4^{\circ} \mathrm{C}\right)$ and continued until the end of 24th h. However, in Zarfam seedlings after cold treatment, no significant difference was observed compared to normal growth conditions (Safaei et al., 2018). This phenotypic change could reveal the Zarfam cultivar's resistance and the Sarigol cultivar's sensitivity to cold stress.
Observations in this study indicated that chilling temperature $\left(4{ }^{\circ} \mathrm{C}\right)$ did not have a phenotypically significant effect on both rapeseed cultivars. Nevertheless, slight dehydration was observed at the beginning of stress in sensitive cultivar (Sarigol). However, this temperature did not have a noticeable effect on the plant phenotypically and did not lead to plant death within $48 \mathrm{~h}$ (Fig. 6). However, examining the response at the molecular level can reveal more differences.

\subsection{The expression patterns of the BnCSD1 and BnCAT1}

Among antioxidant enzymes, SOD is the first line of cellular defense against ROS that primarily scavenges superoxide radicals and converts them to hydrogen peroxide (Kim et al., 2010). The expression patterns of the BnCSD1 gene were examined under cold stress at $4^{\circ} \mathrm{C}$ for $48 \mathrm{~h}$ (Fig. 7). The results showed increased expression of this gene in both cultivars of rapeseed, Zarfam (tolerant), and Sarigol (sensitive). The present study observed that $4 \mathrm{~h}$ after exposure to stress, due to the stress and increased production of free radical superoxide, the expression level of the BnCSD1 gene in both cultivars increased. After $8 \mathrm{~h}$, the sensitive plant could not maintain $B n C S D 1$ expression. As a result, a decrease in gene expression was observed, and this amount remained almost steady for $12 \mathrm{~h}$ after stress. Conversely, the BnCSD 1 expression level remained high in the tolerant cultivar, and $12 \mathrm{~h}$ after stress exposure, the highest expression level of this gene was observed. Initial rapid reaction to detoxification of ROS is necessary to maintain the Calvin cycle and transpiration (Yabuta et al., 2002). It seems that by producing high levels of BnCSDI at the 12th h of stress exposure, the tolerant plant has counteracted quickly with the production of superoxide radicals. Finally, because of the plant's stress adaptation, the BnCSD1 expression level was reduced and almost stabilized at 24 and $48 \mathrm{~h}$. Nevertheless, at the same time, the amount of $B n C S D 1$ in Sarigol increased. Therefore, it seems that the sensitive plant was still trying to cope with stressful conditions. Since SOD is produced in response to $\mathrm{O}_{2}{ }^{-}$ free radicals, it appears that tolerant plants' response to this free radical was more capable, stable, and rapid. These changes depend on the inhibitory power of the antioxidant system and the presence of superoxide free radicals in the two cultivars. In other words, the amount of free radical production may be different between the two cultivars. SOD activity was significantly increased in rapeseed under cold stress conditions (He et al., 2021). In tomato (Solanum lycopersicum), overexpression of the StSOD1 gene led to tolerance against $4{ }^{\circ} \mathrm{C}$ stress (Che et al., 2020). Another study on the SOD gene's expression profile also confirmed its increased expression under cold stress (Hu et al., 2019). A higher accumulation of SiCSD was observed in leaves rapidly exposed to cold $\left(4^{\circ} \mathrm{C}\right)$ and drought stress, which may make an urgent mechanism to detoxify ROS and protect against environmental stress. Also, the $\operatorname{csd} 1$ and $\operatorname{csd} 2$ mutations resulted in resistance and increased $\mathrm{H}_{2} \mathrm{O}_{2}$ accumulation in rice (Li et al., 2019).

It has been revealed that expression of $C A T$ and $A P X$ genes is induced after treatments with cold, oxidative stresses, and ABA (Du et al., 2008). BnCAT1 is a significant player in the scavenging of $\mathrm{H}_{2} \mathrm{O}_{2}$ produced under various environmental 

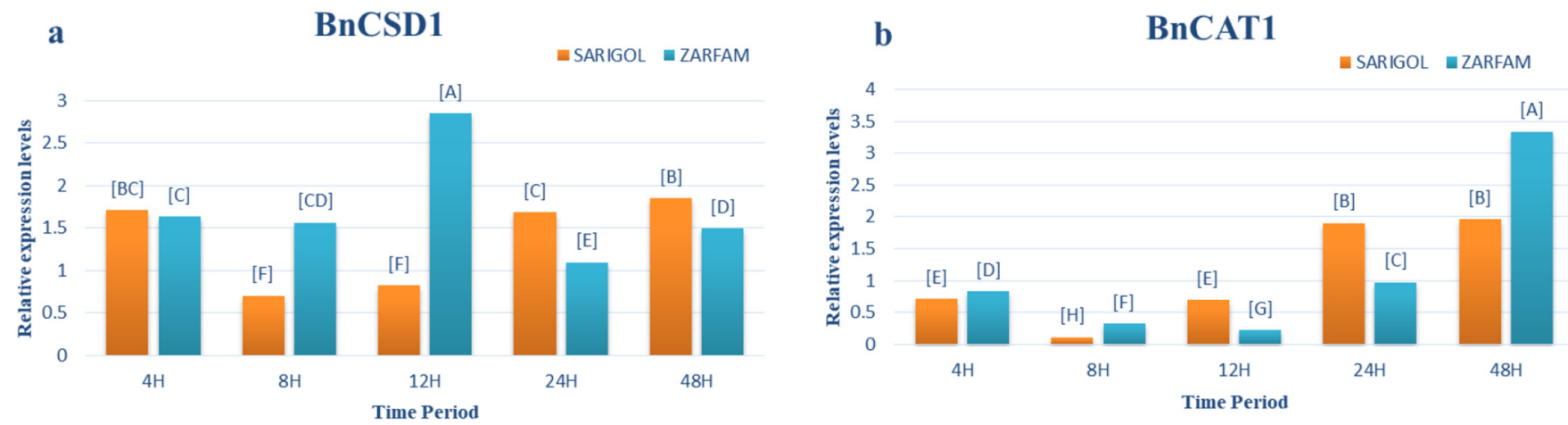

Fig. 7. Expression pattern of genes under $4{ }^{\circ} \mathrm{C}$ cold treatment by Real-Time PCR in Zarfam and Sarigol cultivars. The cyan histogram represents the Zarfam (tolerant), and the orange histogram represents the Sarigol (sensitive) cultivars. The X-axis represents the time after $4{ }^{\circ} \mathrm{C}$ cold exposure, and the Y-axis represents the relative expression level of BnCAT1 and BnCSD1 genes. (a) Expression pattern of BnCSD1. (b) Expression pattern of BnCAT1. The different uppercase letters are significantly different at the 0.05 level.

stresses (Xu et al., 2013). Examining the BnCAT1 gene expression patterns during cold stress of $4{ }^{\circ} \mathrm{C}$ for $48 \mathrm{~h}$ showed the increase of this gene's expression in both cultivars. Initially, $4 \mathrm{~h}$ after exposure to stress, a slight increase in the expression level was observed in both cultivars. Next, a decreasing trend was observed, especially in the tolerant cultivar. This decreasing trend continued up to $12 \mathrm{~h}$ after the stress exposure and even approached zero. Probably, because the amount of hydrogen radicals at the beginning of the stress is less than the number of superoxide radicals, BnCAT1 expression occurs to a lesser extent during this time period. In the tolerant plant, $12 \mathrm{~h}$ after cold stress, the highest amount of $B n C S D 1$ expression level was observed, and the lowest amount of BnCATl expression was seen at the same time. Nevertheless, after $24 \mathrm{~h}$, an increasing trend was observed again and achieved the highest value in $48 \mathrm{~h}$ (Fig. 7). However, this upward trend in the sensitive cultivar started earlier than the 12 th $\mathrm{h}$ of stress treatment, and it increased and stabilized at 24th and 48th h. On the other hand, despite the rise of BnCSD1 expression level, which occurred mostly in the early hours, BnCATI's expression level increased in the later hours. This phenomenon can be due to two possible reasons: first, as a result of protein interactions revealed, other enzymes are directly related to catalase, such as APX and GR, and therefore probably at the beginning of the stress, these enzymes perform the activity of removing hydrogen peroxide. For example, an examination of Saccharum spontaneum CAT3, CAT1, and $C A T 2$ genes revealed that they were significantly upregulated under chilling stress. $G P X$ and $G R$ genes were upregulated upon low-temperature stress (Selvarajan et al., 2018). Second, as mentioned, catalase is activated at high concentrations of $\mathrm{H}_{2} \mathrm{O}_{2}$; therefore, this substance's concentration may have increased over time (SOD activity also produces $\mathrm{H}_{2} \mathrm{O}_{2}$ ). As a result, the plant raised the expression level of the catalase gene in the last hour. Considering the substrate for CAT activity is $\mathrm{H}_{2} \mathrm{O}_{2}$, a by-product of SOD action, their functions should be coupled to achieve a synergistic effect on stress tolerance (Xu et al., 2014). Published studies also confirmed that cold stress increased catalase and superoxide dismutase activity in B. oleracea (Soengas et al., 2018; Wojciechowska et al., 2013). Another study on sweet potato (Ipomoea batatas) indicated Overexpression of $I b C A T 2$ gave salt and drought tolerance in Escherichia coli and Saccharomyces cerevisiae. The positive response of $I b C A T 2$ to abiotic stresses implied IbCAT2 might carry out a significant function in stress responses (Huang et al., 2020). Abiotic stress disrupts the metabolic balance of plant cells, resulting in a loss of balance of ROS production and scavenging in the cytoplasm, chloroplasts and mitochondria in plants. Therefore, the physiological process of ROS toxic concentration in plants could be reduced by developing a complicated and efficient ROS scavenging and antioxidant defense system (Ritonga and Chen, 2020).

\section{Conclusion}

This study identified and investigated the antioxidant system's possible interactions and microRNAs targeting $B n C A T 1$ and BnCSD1 genes using online databases. The effect of cold stress $\left(4^{\circ} \mathrm{C}\right)$ in $48 \mathrm{~h}$ on these genes' expression was subsequently examined. The protein interactions revealed extensive and close interactions within the antioxidant system, and it appears that these systems act interdependently in response to stresses. In other words, not only did the CATs and CSDs enzymes have a relationship together, but they also interacted directly with APX and GR groups. MicroRNAs are also critical factors affecting genes' expression during stress and play a fundamental role in regulating genes' expression after transcription. This study also showed that BnCATl and $B n C S D 1$ genes are targeted by many highly conserved microRNAs in plants. Using the results of this research can be performed a complete and comprehensive analysis in future research by investigating the expression behavior of these microRNAs under cold stress in a tolerant and sensitive cultivar of rapeseed. BnCAT1 and BnCSD1 genes' expression increased during the stress in both sensitive and tolerant plants, but this increase was more noticeable in a tolerant cultivar. The highest expression of the BnCSD1 was observed in the early hours of stress exposure, especially at 12 th h. In other words, the tolerant plant's defense system seems to act faster and neutralize the superoxide radicals efficiently. However, the product of this reaction is the hydrogen peroxide radical. In contrast, the BnCAT1 responsible gene for maintaining $\mathrm{H}_{2} \mathrm{O}_{2}$ radicals had the highest expression level in the 48th $\mathrm{h}$. 
Therefore, cooperation BnCAT1 with BnCSD1 enzyme can improve an effective defense system facing free radicals. However, other components of the antioxidant defense system should be studied to understand these mechanisms better, such as APX enzymes and GR. They could be the subject of subsequent research; therefore, the interactive nature of these enzymes and the systems involved in responding to reactive oxygen species and cold stress could be better understood with such experiments.

\section{Supplementary Material}

Table S1. Identified microRNAs affecting CAT1 gene using psRNATarget software with the expected value 4 .

Table S2. Identified microRNAs affecting CSD1 gene using psRNATarget software with the expected value 4 .

The Supplementary Material is available at http://www.ocljournal.org/10.1051/ocl/2021051/olm.

Acknowledgments. This work was supported by the Iran National Science Foundation (Grant number: 95814286).

Conflict of interest. The authors declare that there is no conflict of interest.

\section{References}

Alscher RG, Erturk N, Heath LS. 2002. Role of superoxide dismutases (SODs) in controlling oxidative stress in plants. $J$ Exp Bot 53: 1331-1341.

Bartel DP. 2004. MicroRNAs: Genomics, biogenesis, mechanism, and function. Cell 116: 281-297.

Cao X, Wu Z, Jiang F, Zhou R, Yang Z. 2014. Identification of chilling stress-responsive tomato microRNAs and their target genes by high-throughput sequencing and degradome analysis. $B M C$ Genom 15: 1130.

Cavallini G, Sgarbossa A, Parentini I, et al. 2016. Dolichol: A component of the cellular antioxidant machinery. Lipids 51: $477-486$.

Che Y, Zhang N, Zhu X, Li S, Wang S, Si H. 2020. Enhanced tolerance of the transgenic potato plants overexpressing $\mathrm{Cu} / \mathrm{Zn}$ superoxide dismutase to low temperature. Sci Hortic 261: 108949.

Dai X, Zhuang Z, Zhao PX. 2018. psRNATarget: A plant small RNA target analysis server (2017 release). Nucl Acids Res 46: W49W54.

Du YY, Wang PC, Chen J, Song CP. 2008. Comprehensive functional analysis of the catalase gene family in Arabidopsis thaliana. J Integr Plant Biol 50: 1318-1326.

Epstein E, Bloom AJ. 2004. Mineral nutrition of plants: Principles and perspectives. Sinauer.

Gao F, Wang N, Li H, et al. 2016. Identification of drought-responsive microRNAs and their targets in Ammopiptanthus mongolicus by using high-throughput sequencing. Sci Rep 6: 1-16.

Gupta S, Dong Y, Dijkwel PP, Mueller-Roeber B, Gechev TS. 2019. Genome-wide analysis of ROS antioxidant genes in resurrection species suggest an involvement of distinct ROS detoxification systems during desiccation. Int J Mol Sci 20: 3101.

Gusta L, Wisniewski M, Nesbitt N, Gusta M. 2004. The effect of water, sugars, and proteins on the pattern of ice nucleation and propagation in acclimated and nonacclimated canola leaves. Plant Physiol 135: 1642-1653.
Hasanuzzaman M, Bhuyan M, Zulfiqar F, et al. 2020. Reactive oxygen species and antioxidant defense in plants under abiotic stress: Revisiting the crucial role of a universal defense regulator. Antioxidants 9.

He H, Lei Y, Yi Z, et al. 2021. Study on the mechanism of exogenous serotonin improving cold tolerance of rapeseed (Brassica napus L.) seedlings. Plant Growth Regul 94: 161-170.

Hu X, Hao C, Cheng Z-M, Zhong Y. 2019. Genome-wide identification, characterization, and expression analysis of the grapevine superoxide dismutase (SOD) family. Int J Genom 2019.

Huang S, Zhou J, Gao L, Tang Y. 2020. Plant miR397 and its functions. Funct Plant Biol 48: 361-370.

Kalisz A, Pokluda R, Jezdinský A, et al. 2016. Chilling-induced changes in the antioxidant status of basil plants. Acta Physiol Plantarum 38: 196.

Kim MD, Kim YH, Kwon SY, Yun DJ, Kwak SS, Lee HS. 2010. Enhanced tolerance to methyl viologen-induced oxidative stress and high temperature in transgenic potato plants overexpressing the CuZnSOD, APX and NDPK2 genes. Physiologia Plant 140: 153-162.

Koc I, Filiz E, Tombuloglu H. 2015. Assessment of miRNA expression profile and differential expression pattern of target genes in cold-tolerant and cold-sensitive tomato cultivars. Biotechnol Biotechnol Equip 29: 851-860.

Kumar S, Stecher G, Li M, Knyaz C, Tamura K. 2018. MEGA X: Molecular evolutionary genetics analysis across computing platforms. Mol Biol Evolut 35: 1547-1549.

Lee H, Chawla HS, Obermeier C, Dreyer F, Abbadi A, Snowdon R. 2020. Chromosome-scale assembly of winter oilseed rape Brassica napus. Front Plant Sci 11: 496.

Li S, Yu X, Lei N, et al. 2017. Genome-wide identification and functional prediction of cold and/or drought-responsive lncRNAs in cassava. Sci Rep 7: 45981.

Li Y, Cao XL, Zhu Y, et al. 2019. Osa-miR398b boosts $\mathrm{H}_{2} \mathrm{O}_{2}$ production and rice blast disease-resistance via multiple superoxide dismutases. New Phytol 222: 1507-1522.

Liu H-H, Tian X, Li Y-J, Wu C-A, Zheng C-C. 2008. Microarraybased analysis of stress-regulated microRNAs in Arabidopsis thaliana. Rna 14: 836-843.

Liu Y, Wang K, Li D, Yan J, Zhang W. 2017. Enhanced cold tolerance and tillering in switchgrass (Panicum virgatum $\mathrm{L}$.) by heterologous expression of Osa-miR393a. Plant Cell Physiol 58: 2226-2240.

Megha S, Basu U, Joshi RK, Kav NN. 2018. Physiological studies and genome-wide microRNA profiling of cold-stressed Brassica napus. Plant Physiol Biochem 132: 1-17.

Millar AA, Waterhouse PM. 2005. Plant and animal microRNAs: Similarities and differences. Funct Integr Genom 5: 129-135.

Moran Y, Agron M, Praher D, Technau U. 2017. The evolutionary origin of plant and animal microRNAs. Nat Ecol Evolut 1: 0027.

Pandey S, Fartyal D, Agarwal A, et al. 2017. Abiotic stress tolerance in plants: Myriad roles of ascorbate peroxidase. Front Plant Sci 8: 581.

Parkin IA, Gulden SM, Sharpe AG, et al. 2005. Segmental structure of the Brassica napus genome based on comparative analysis with Arabidopsis thaliana. Genetics 171: 765-781.

Raza A. 2020. Eco-physiological and biochemical responses of rapeseed (Brassica napus L.) to abiotic stresses: consequences and mitigation strategies. J Plant Growth Regul: 1-21.

Raza A, Razzaq A, Mehmood SS, et al. 2019. Impact of climate change on crops adaptation and strategies to tackle its outcome: A review. Plants 8: 34 .

Raza A, AshrafF, Zou X, Zhang X, TosifH. 2020a. Plant adaptation and tolerance to environmental stresses: Mechanisms and perspectives. In. Plant ecophysiology and adaptation under climate change: mechanisms and perspectives I. Springer, pp. 117-145. 
Raza A, Hafeez MB, Zahra N, et al. 2020b. The plant family Brassicaceae: Introduction, biology, and importance. In: The plant family Brassicaceae. Springer, pp. 1-43.

Raza A, Su W, Gao A, et al. 2021. Catalase (CAT) gene family in rapeseed (Brassica napus L.): Genome-wide analysis, identification, and expression pattern in response to multiple hormones and abiotic stress conditions. Int J Mol Sci 22: 4281.

Rezaie R, Mandoulakani BA, Fattahi M. 2020. Cold stress changes antioxidant defense system, phenylpropanoid contents and expression of genes involved in their biosynthesis in Ocimum basilicum L. Sci Rep 10: 1-10.

Ritonga FN, Chen S. 2020. Physiological and molecular mechanism involved in cold stress tolerance in plants. Plants 9: 560.

Safaei M, Lahiji HS, Kumleh HH. 2018. The effect of cold stress on the expression of several genes associated with cold signal transduction system pathway in cultivars of canola (Brassica napus). Ind J Forensic Med Toxicol 12.

Schmittgen TD, Livak KJ. 2008. Analyzing real-time PCR data by the comparative C T method. Nat Protoc 3: 1101.

Selvarajan D, Mohan C, Dhandapani V, et al. 2018. Differential gene expression profiling through transcriptome approach of Saccharum spontaneum L. under low temperature stress reveals genes potentially involved in cold acclimation. 3 Biotech 8: 195.

Sewelam N, Kazan K, Schenk PM. 2016. Global plant stress signaling: Reactive oxygen species at the cross-road. Front Plant Sci 7: 187.

Shannon P, Markiel A, Ozier O, et al. 2003. Cytoscape: A software environment for integrated models of biomolecular interaction networks. Genom Res 13: 2498-2504.

Sharma I. 2014. Catalase: A versatile antioxidant in plants. In: Ahmad P, ed. Oxidative damage to plants. Academic Press, pp. 131-148.

Sharma P, Jha AB, Dubey RS, Pessarakli M. 2012. Reactive oxygen species, oxidative damage, and antioxidative defense mechanism in plants under stressful conditions. J Bot 2012.

Smirnof N. 1993. The role of active oxygen in the response of plants to water deficit and desiccation. New Phytol 125: 27-58.

Soengas P, Rodríguez VM, Velasco P, Cartea ME. 2018. Effect of temperature stress on antioxidant defenses in Brassica oleracea. ACS Omega 3: 5237-5243.

Su W, Raza A, Gao A, et al. 2021. Genome-wide analysis and expression profile of superoxide dismutase (SOD) gene family in rapeseed (Brassica napus L.) under different hormones and abiotic stress conditions. Antioxidants 10: 1182.

Sun X, Fan G, Su L, et al. 2015. Identification of cold-inducible microRNAs in grapevine. Front Plant Sci 6: 595.

Sunkar R, Zhu J-K. 2004. Novel and stress-regulated microRNAs and other small RNAs from Arabidopsis. The Plant Cell 16: 2001-2019.
Szklarczyk D, Gable AL, Lyon D, et al. 2019. STRING v11: Proteinprotein association networks with increased coverage, supporting functional discovery in genome-wide experimental datasets. $\mathrm{Nucl}$ Acids Res 47: D607-D613.

Taghvaei MM, Samizadeh Lahiji H, Bakhtiarizadeh MR, Mohsenzadeh Golafazani M. 2019. Bioinformatics analysis of microRNAs related to cold stress and their effects on proteins associated with fatty acids metabolism in rapeseed (Brassica napus L.). J Crop Biotechnol 9: 41-58.

Thomashow MF. 1999. Plant cold acclimation: Freezing tolerance genes and regulatory mechanisms. Ann Rev Plant Biol 50: 571599.

Thompson JD, Higgins DG, Gibson TJ. 1994. CLUSTAL W: Improving the sensitivity of progressive multiple sequence alignment through sequence weighting, position-specific gap penalties and weight matrix choice. Nucl Acids Res 22: 46734680 .

Wanasundara J, Tan S, Alashi A, Pudel F, Blanchard C. 2017. Proteins from canola/rapeseed: Current status. Sustainable protein sources. Academic Press, pp. 285-304.

Wang B, Sun Y-F, Song N, et al. 2014. MicroRNAs involving in cold, wounding and salt stresses in Triticum aestivum L. Plant Physiol Biochem 80: 90-96.

Wojciechowska R, Hanus-Fajerska EJ, Kolton A, Kaminska I, Grabowska A, Kunicki E. 2013. The effect of seedling chilling on glutathione content, catalase and peroxidase activity in Brassica oleracea L. var. italica. Acta Soc Bot Pol 82.

Xie X, He Z, Chen N, Tang Z, Wang Q, Cai Y. 2019. The roles of environmental factors in regulation of oxidative stress in plant. BioMed Res Int 2019.

Xu J, Duan X, Yang J, Beeching JR, Zhang P. 2013. Coupled expression of $\mathrm{Cu} / \mathrm{Zn}$-superoxide dismutase and catalase in cassava improves tolerance against cold and drought stresses. Plant Signal Behav 8: e24525.

Xu J, Yang J, Duan X, Jiang Y, Zhang P. 2014. Increased expression of native cytosolic $\mathrm{Cu} / \mathrm{Zn}$ superoxide dismutase and ascorbate peroxidase improves tolerance to oxidative and chilling stresses in cassava (Manihot esculenta Crantz). BMC Plant Biol 14: 1-14.

Yabuta Y, Motoki T, Yoshimura K, Takeda T, Ishikawa T, Shigeoka S. 2002. Thylakoid membrane-bound ascorbate peroxidase is a limiting factor of antioxidative systems under photo-oxidative stress. Plant $J$ 32: 915-925.

Zhang Y, Zhu X, Chen X, et al. 2014. Identification and characterization of cold-responsive microRNAs in tea plant (Camellia sinensis) and their targets using high-throughput sequencing and degradome analysis. BMC Plant Biol 14: 271.

Cite this article as: Taghvaei MM, Samizadeh Lahiji H, Mohsenzadeh Golfazani M. 2022. Evaluation of expression changes, proteins interaction network, and microRNAs targeting catalase and superoxide dismutase genes under cold stress in rapeseed (Brassica napus L.). OCL 29: 3. 